\title{
Lesser Severity of Recurrent Takotsubo Cardiomyopathy While Taking Angiotensin II Receptor Blocker and Beta Blocker
}

\author{
K. Nicole Zagelbaum ${ }^{\mathrm{a}}$, Ahmed AlBadri ${ }^{\mathrm{b}}$, Chrisandra Shufelt ${ }^{\mathrm{c}}$, Janet Wei ${ }^{\mathrm{c}}$, \\ C. Noel Bairey Merz ${ }^{\mathrm{c}, \mathrm{d}}$
}

\begin{abstract}
Takotsubo cardiomyopathy (TC) is characterized by transient systolic and diastolic dysfunction, ventricular wall motion abnormalities and troponin elevation. The most common presenting symptoms are acute chest pain and dyspnea. The etiology is unknown but believed to be related to a surge in catecholamines as it is commonly associated with a preceding physical or emotional stress. Due to the lack of specific treatment, recurrence occurs in $2-12 \%$ of patients per year. We present a case of a patient with TC subsequently treated with an angiotensin II receptor blocker (ARB) and beta-adrenergic blocker (beta-blocker). A repeat TC episode 4 months later showed less severely abnormal cardiac enzymes, echocardiogram and overall hospital course. Because our patient experienced a classic episode of TC and a recurrent episode with milder symptoms and lower troponins, we hypothesize her medication regimen was a contributing factor to the milder manifestation of this cardiac syndrome.
\end{abstract}

Keywords: Takotsubo cardiomyopathy; Stress-induced cardiomyopathy; Angiotensin II receptor blocker; Beta-adrenergic blocker

\section{Introduction}

Takotsubo cardiomyopathy (TC) is a type of acute coronary syndrome (ACS) most commonly diagnosed in postmenopausal female patients that is characterized by transient systolic and diastolic dysfunction [1], wall motion abnormalities of the left ventricular apex and troponin elevations despite normal coronary arteries $[2,3]$. There are four types based on cardiac

Manuscript submitted May 2, 2018, accepted May 16, 2018

${ }^{a}$ Westchester Medical Center, Valhalla, NY 10595, USA

bEmory University, Atlanta, GA 30322, USA

'Barbra Streisand Women's Heart Center, Cedars-Sinai Smidt Heart Institute, Los Angeles, CA 90048, USA

${ }^{\mathrm{d}}$ Corresponding Author: C. Noel Bairey Merz, Barbra Streisand Women's Heart Center, Cedars-Sinai Smidt Heart Institute, 127 S San Vicente Blvd, Suite A3906, Los Angeles, CA 90048, USA.

Email: noel.baireymerz@cshs.org

doi: https://doi.org/10.14740/jmc3079w catheterization findings including the apical type (> 80\% of cases), midventricular type, basal type and focal type [4]. The most common presenting symptoms are acute chest pain and dyspnea while associated clinical findings include elevation in cardiac enzymes and electrocardiogram (ECG) changes $[5,6]$. Other laboratory abnormalities include elevated brain natriuretic peptide (BNP) and $\mathrm{BNP} /$ peak troponin ratio when compared to ST-elevation myocardial infarction patients [7]. There are no randomized trials or expert consensus for medical management and treatment.

Although the etiology of TC is not clear, it is thought to be related to a catecholamine surge from a preceding physical or emotional stress. However, over $15-20 \%$ of TC episodes do not have clear triggers [8]. Catecholamine overload may also lead to chronic inflammatory states and oxidative injury as myocardial biopsies have demonstrated increased fibrosis and inflammatory cell infiltration in TC patients [9]. Estrogen may also play a role as meta-analysis has demonstrated about $80 \%$ of cases occur in women $>50$ years [10] and women represent $90 \%$ of cases overall [8].

In 2012 over 6,000 cases of TC were reported in the United States with increasing annual incidence [11] representing $1-2 \%$ of all myocardial infarctions [12]. Roughly $2-12 \%$ of patients experience recurrent episodes [7, 8, 13]. Mortality is similar compared to patients with ACS from other causes [14, 15] and increased compared to control subject with reported chest pain [4]. Common complications include cardiogenic shock [16], arrhythmias [7] and death [5].

\section{Case Report}

A 59-year-old female with past medical history of hypertension and surgical menopause at age 35 secondary to bilateral oophorectomy presented to our clinic for follow-up evaluation of chest pain. Six months prior, she presented to the emergency department for new and severe epigastric pain which lasted for $12 \mathrm{~h}$. ECG was significant for ST-depressions in the septal leads concerning for acute posterior myocardial infarction. Laboratory tests were significant for elevated troponin I (TnI) of $13 \mathrm{ng} / \mathrm{mL}$ and B-type natriuretic peptide (BNP) $>600 \mathrm{pg} /$ $\mathrm{mL}$. Transthoracic echocardiogram (TTE) demonstrated an estimated left ventricular ejection fraction of 35\% with hypokinesis of the mid and distal segments and apical dyskinesis con- 


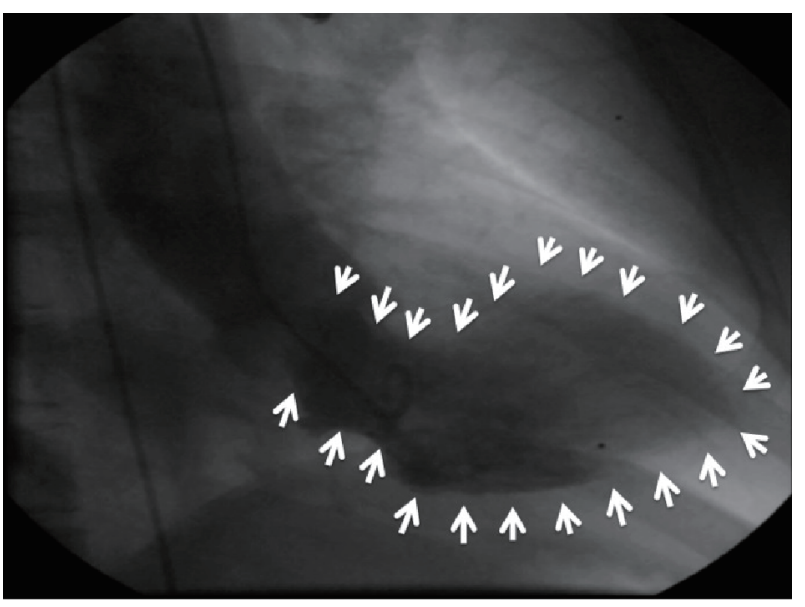

Figure 1. Angiogram during the first episode demonstrating marked apical ballooning and hypercontracting base (white arrows).

sistent with TC. Catheterization revealed markedly elevated left ventricular end diastolic pressure of $26 \mathrm{~mm} \mathrm{Hg}$ with apical ballooning (Fig. 1). No obstructive coronary artery disease was seen. She was discharged home on losartan and carvedilol.

Four months later, she experienced similar episode of severe epigastric and chest pain lasting for hours. ECG showed nonspecific ST abnormalities. Laboratory tests revealed mildly elevated TnI $(0.7 \mathrm{ng} / \mathrm{mL})$ and BNP within normal limits (62 $\mathrm{pg} / \mathrm{mL}$ ). TTE demonstrated no wall motion abnormalities and a left ventricular ejection fraction of $65-70 \%$. Repeat catheterization showed no obstructive coronary artery disease. Interestingly, she denied any recent physical or emotional stressors related to either episode.

She was seen at our clinic 1 month later for cardiology consultation. She had no complaints of chest pain or dyspnea at time of presentation and reported being able to exercise rigorously daily without experiencing cardiovascular symptoms. Daily home medications included carvedilol $3.125 \mathrm{mg}$ twice a day, losartan $25 \mathrm{mg}$, isosorbide mononitrate $30 \mathrm{mg}$, aspirin 81 $\mathrm{mg}$, and oral estradiol $2 \mathrm{mg}$ daily, and nitroglycerin 0.4 sublingual tablets as needed. Following this consultation, the angiotensin II receptor blocker (ARB) (losartan) was discontinued and she was started on the angiotensin-converting-enzyme inhibitor (ACEI) ramipril $2.5 \mathrm{mg}$ twice daily. The oral estradiol was stopped due to concern of thrombosis. She has now been symptom free for 6 months and able to exercise regularly without experiencing symptoms.

\section{Discussion}

The pathogenesis of TC is unclear though several hypotheses exist. It could be due to excessive production of epinephrine after beta-adrenergic response resulting in a decline of cardiac myocyte activity and inefficient myocardial function [17]. This may also explain the predilection and worse outcomes in women as myocytes in males may have greater resilience and restorative properties than females [18]. Mental stressors and subsequent increases in epinephrine and catecholamine levels also impact endothelial function and may result in catecholaminerelated myocyte toxicity, coronary microvascular dysfunction and coronary microvascular vascular spasm [19]. These theories are supported by the relationship between TC and estrogen withdrawal, as these patients lose the protective qualities of estrogen from catecholamine toxicity, calcium overload and oxidative stress. Fatty acid metabolism may also play a role as one retrospective study utilizing data from a national patient registry found patients with $\mathrm{TC}$ were less likely to be treated for hyperlipidemia at the time of presentation [15].

Several treatment strategies have been explored. As a result of the proposed mechanism involving catecholamine surge, beta-blockers have been explored as a potential treatment. To date, large prospective observational studies have found no improvement in recurrence rates or mortality when treating patients with normal doses of beta-blockers [8]. However, patients with left ventricular outflow obstruction [7] or interventricular pressure gradients may experience greater benefit [20]. Current understanding is that clinicians should choose combined alpha and beta-blockers such as carvedilol to minimize vasoconstriction due to alpha effects [7]. In addition, beta-blockers have been found to assist in associated complications of TC including cardiogenic shock, ventricular arrhythmias and death [16].

Overall, a reduced ejection fraction is noted in $86.5 \%$ of patients with TC [8] and therefore ACEI and ARBs may play a role in treatment [2]. A retrospective analysis in a large multi-center international registry including 1,118 patients with medications prescribed at hospital discharge after a TC event found improved survival rates 1 year after TC event in patients taking ACEI and ARBs but not beta-blockers [8]. A systematic review also found that ACEI/ARB prescriptions are associated with decreased recurrence rate, but not beta-blocker prescriptions. However, both studies did not distinguish between types of beta-blockers (selective vs. non-selective) or combined beta-blocker and ACEI/ARB therapy [21]. Another retrospective review including 66 patients at two hospitals found that patients taking ACEI prior to admission did not develop critical complications including arrhythmia, cardiogenic shock and death [16]. Long-term clinical management to minimize recurrence rates and optimize overall prognosis is less clear. We substituted an ACEI for the ARB in this patient because large multi-center registries have found an associated decreased mortality and recurrence of TC $[8,16]$.

Information surrounding recurrent episodes of TC is limited. Some estimates have found recurrent episodes to occur between 3 weeks to 3.8 years and are associated with consistently poor left ventricular ejection fractions of $\leq 40 \%$ [14]. There are no clinical trials exploring medical management for effectively minimizing recurrent episodes. Therefore, assessing the efficacy of medical interventions including ACEI/ARBs and beta-blockers in relation to recurrent episode severity represents a potential point of interest for future exploration [13].

\section{Conclusions}

TC is a form of ACS where pathophysiology and optimal treatment is unknown. Recurrence is observed in $2-12 \%$ and 
there is little information surrounding medical interventions to optimize outcomes within this subpopulation. Because the condition is associated with increased morbidity and mortality, further exploration into management and treatment plans is warranted. We present a case where ARBs and beta-blockers dampened the symptoms of recurrent TC.

\section{Grant Support}

This work was supported by contracts from the National Heart, Lung and Blood Institutes nos. N01-HV-68161, N01-HV-68162, N01-HV-68163, N01-HV-68164, grants U0164829, U01 HL649141, U01 HL649241, K23HL105787, T32HL69751, R01 HL090957, 1R03AG032631 from the National Institute on Aging, GCRC grant MO1-RR00425 from the National Center for Research Resources, the National Center for Advancing Translational Sciences Grant UL1TR000124 and UL1TR000064, and grants from the Gustavus and Louis Pfeiffer Research Foundation, Danville, NJ, The Women's Guild of Cedars-Sinai Medical Center, Los Angeles, CA, The Ladies Hospital Aid Society of Western Pennsylvania, Pittsburgh, PA, and QMED, Inc., Laurence Harbor, NJ, the Edythe L. Broad and the Constance Austin Women's Heart Research Fellowships, Cedars-Sinai Medical Center, Los Angeles, California, the Barbra Streisand Women's Cardiovascular Research and Education Program, Cedars-Sinai Medical Center, Los Angeles, The Society for Women's Health Research (SWHR), Washington, D.C., The Linda Joy Pollin Women's Heart Health Program, and the Erika J. Glazer Women's Heart Health Initiative, Cedars-Sinai Medical Center, Los Angeles, California.

\section{References}

1. Medeiros K, O'Connor MJ, Baicu CF, Fitzgibbons TP, Shaw P, Tighe DA, Zile MR, et al. Systolic and diastolic mechanics in stress cardiomyopathy. Circulation. 2014;129(16):1659-1667.

2. Prasad A, Lerman A, Rihal CS. Apical ballooning syndrome (Tako-Tsubo or stress cardiomyopathy): a mimic of acute myocardial infarction. Am Heart J. 2008;155(3):408-417.

3. Akashi YJ, Goldstein DS, Barbaro G, Ueyama T. Takotsubo cardiomyopathy: a new form of acute, reversible heart failure. Circulation. 2008;118(25):2754-2762.

4. Templin C, Napp LC, Ghadri JR. Takotsubo syndrome: underdiagnosed, underestimated, but understood? J Am Coll Cardiol. 2016;67(16):1937-1940.

5. Gopalakrishnan M, Hassan A, Villines D, Nasr S, Chandrasekaran M, Klein LW. Predictors of short- and longterm outcomes of Takotsubo cardiomyopathy. Am J Cardiol. 2015;116(10):1586-1590.

6. Frangieh AH, Obeid S, Ghadri JR, Imori Y, D'Ascenzo F, Kovac M, Ruschitzka F, et al. ECG criteria to differentiate between Takotsubo (Stress) cardiomyopathy and myocardial infarction. J Am Heart Assoc. 2016;5(6):e003418.

7. Bietry R, Reyentovich A, Katz SD. Clinical manage- ment of takotsubo cardiomyopathy. Heart Fail Clin. 2013;9(2):177-186, viii.

8. Templin C, Ghadri JR, Diekmann J, Napp LC, Bataiosu DR, Jaguszewski M, Cammann VL, et al. Clinical Features and Outcomes of Takotsubo (Stress) Cardiomyopathy. N Engl J Med. 2015;373(10):929-938.

9. Nef HM, Mollmann H, Kostin S, Troidl C, Voss S, Weber M, Dill T, et al. Tako-Tsubo cardiomyopathy: intraindividual structural analysis in the acute phase and after functional recovery. Eur Heart J. 2007;28(20):2456-2464.

10. Deshmukh A, Kumar G, Pant S, Rihal C, Murugiah K, Mehta JL. Prevalence of Takotsubo cardiomyopathy in the United States. Am Heart J. 2012;164(1):66-71 e61.

11. Minhas AS, Hughey AB, Kolias TJ. Nationwide trends in reported incidence of Takotsubo cardiomyopathy from 2006 to 2012. Am J Cardiol. 2015;116(7):1128-1131.

12. Kurowski V, Kaiser A, von Hof K, Killermann DP, Mayer B, Hartmann F, Schunkert H, et al. Apical and midventricular transient left ventricular dysfunction syndrome (tako-tsubo cardiomyopathy): frequency, mechanisms, and prognosis. Chest. 2007;132(3):809-816.

13. Elesber AA, Prasad A, Lennon RJ, Wright RS, Lerman A, Rihal CS. Four-year recurrence rate and prognosis of the apical ballooning syndrome. J Am Coll Cardiol. 2007;50(5):448-452.

14. Sharkey SW, Windenburg DC, Lesser JR, Maron MS, Hauser RG, Lesser JN, Haas TS, et al. Natural history and expansive clinical profile of stress (tako-tsubo) cardiomyopathy. J Am Coll Cardiol. 2010;55(4):333-341.

15. Tornvall P, Collste O, Ehrenborg E, Jarnbert-Petterson H. A case-control study of risk markers and mortality in Takotsubo stress cardiomyopathy. J Am Coll Cardiol. 2016;67(16):1931-1936.

16. Regnante RA, Zuzek RW, Weinsier SB, Latif SR, Linsky RA, Ahmed HN, Sadiq I. Clinical characteristics and four-year outcomes of patients in the Rhode Island Takotsubo Cardiomyopathy Registry. Am J Cardiol. 2009;103(7):1015-1019.

17. Lyon AR, Rees PS, Prasad S, Poole-Wilson PA, Harding SE. Stress (Takotsubo) cardiomyopathy - a novel pathophysiological hypothesis to explain catecholamineinduced acute myocardial stunning. Nat Clin Pract Cardiovasc Med. 2008;5(1):22-29.

18. Stollberger C, Finsterer J. Why does takotsubo ("broken heart syndrome") affect more females than males? Int J Cardiol. 2011;147(1):175-176.

19. Merchant EE, Johnson SW, Nguyen P, Kang C, Mallon WK. Takotsubo cardiomyopathy: a case series and review of the literature. West J Emerg Med. 2008;9(2):104-111.

20. Kyuma M, Tsuchihashi K, Shinshi Y, Hase M, Nakata T, Ooiwa H, Abiru M, et al. Effect of intravenous propranolol on left ventricular apical ballooning without coronary artery stenosis (ampulla cardiomyopathy): three cases. Circ J. 2002;66(12):1181-1184.

21. Singh K, Carson K, Usmani Z, Sawhney G, Shah R, Horowitz J. Systematic review and meta-analysis of incidence and correlates of recurrence of takotsubo cardiomyopathy. Int J Cardiol. 2014;174(3):696-701. 